\title{
Malaria in Greece, 1975 to 2010
}

\author{
A Vakali (annita86@windowslive.com) ${ }^{1}$, E Patsoula ${ }^{2}$, G Spanakos ${ }^{1}, K_{\text { Danis }}^{1}$, E Vassalou ${ }^{2}$, N Tegos $^{2}$, A Economopoulou $^{1}$, A Baka $^{1}$, \\ A Pavli ${ }^{1}$, C Koutis ${ }^{3}$, C Hadjichristodoulou ${ }^{4}$, T Kremastinou ${ }^{1,2}$ \\ 1. Hellenic Centre for Diseases Control and Prevention, Athens, Greece \\ 2. National School of Public Health, Athens, Greece \\ 3. Technological Educational Institute of Athens, Athens, Greece \\ 4. Department of Hygiene and Epidemiology, Medical Faculty, University of Thessaly, Greece
}

Citation style for this article:

Vakali A, Patsoula E, Spanakos G, Danis K, Vassalou E, Tegos N, Economopoulou A, Baka A, Pavli A, Koutis C, Hadjichristodoulou C, Kremastinou T. Malaria in Greece, 1975 to 2010. Euro Surveill. 2012;17(47):pii=20322. Available online: http://www.eurosurveillance.org/ViewArticle.aspx?Articleld=20322

Article submitted on 11 June 2012 / published on 22 November 2012

Malaria, which was endemic in Greece in the past, was officially eliminated in 1974 . Since that time and up to 2010, a number of imported cases (ranging from 19 to 76 ) have been annually reported. The total number of reported laboratory-confirmed cases between 1975 and 2010 was 1,419. Plasmodium falciparum was identified in 628 (44\%) of these cases, while $P$. vivax was found in 524 (37\%). Of the total cases, 1,123 (79\%) were male (ratio males vs. females: $3 \cdot 78$ ). Age was only available for 490 cases, of which 352 (72\%) belonged to the 18-40 year-age group. Of the 382 malaria cases reported from 1999 to 2010 for which the region/country of acquisition was known, 210 (55\%) were from Africa and 142 (37\%) from Asia. The massive introduction of economic migrants, in the period from 1990 to 1991 and from 2006 onwards, mainly from countries where malaria is endemic, resulted in the appearance of introduced sporadic cases. In Peloponnese, Central and East Macedonia, Thrace and East Attica, mosquitoes of the genus Anopheles (e.g. Anopheles sacharovi, $A$. superpictus and $A$. maculipenis) that can act as plasmodia vectors are abundant and during the summer of 2011, 27 P. vivax cases were reported in Greek citizens residing in the agricultural area of Evrotas in Lakonia and without travel history. As further $P$. vivax malaria cases occurred in the Lakonia and East Attica areas in 2012, it is becoming urgent to strengthen surveillance and perform integrated mosquito control that will help eliminate the potential risk of malaria reintroduction and reestablishment.

\section{Introduction}

Almost a century has passed, since Ronald Ross [1] and other scientists [2] combined their efforts to eliminate malaria in Greece. From 1905 to 1940, apart from the mountainous areas and the big urban centres, malaria was present in mainland Greece, and on the island of Crete [2] and had become a serious problem up to 1937 with about one to two million cases occurring annually (1 million from 1905-21 and 1-2 million from 1921-37). This had remarkable socioeconomic consequences [2,3]. In 1958 and 1959 malaria control centres were organised and operated in several parts of the country, such as Skala in the Evrotas, the Lakonia region, Lamia in Fthiotida and Provatas in the Serres region in Macedonia. The national malaria control and elimination programmes that were applied especially from 1946 to 1960 resulted in the official recognition of Greece as a malaria-free country in $1974[4,5]$.

Malaria is notifiable in Greece since the 1930s [6] and from that time malaria cases have been diagnosed microscopically by local laboratories, by detecting Plasmodium in the blood. Since the 1960s, blood samples of all suspected cases or cases characterised as positive are also sent to the Malaria Reference Laboratory (MRL) of the National School of Public Health (NSPH) for verification, where thick and thin blood smears are examined. Since 1999, blood samples of suspected positive cases, are also routinely screened by a multiplex polymerase chain reaction (PCR) specific for $P$. falciparum and $P$. vivax [7]. It is always attempted to test the initial sample that triggered suspicion of malaria infection.

After malaria elimination, a surveillance system of laboratory-confirmed malaria cases was established by the Public Health Division of the Greek Ministry of Health (MoH). From 1974 to 1997, all laboratory-confirmed cases were reported to $\mathrm{MoH}$ and related files kept in the ministry's archives. In 1995, however, the responsibility of data collection was officially transferred to the Hellenic Centre for Disease Control and Prevention (HCPCP), but $\mathrm{MoH}$ nevertheless continued recording malaria cases in 1995 and 1996. During these two years, MRL cooperated with $\mathrm{MoH}$ and HCDCP and contributed to cross-check the existing data. Since 1997 to date, all laboratory-confirmed malaria cases are reported to HCDCP where data is maintained in an electronic database.

Surveillance is based on mandatory notification of confirmed cases and passive case detection is performed through hospitals after Plasmodium detection in the hospital laboratories. Doctors in private practice or from non-governmental organisations refer patients to the MRL for laboratory confirmation and subsequently report positive cases to the surveillance authority 
(MoH before 1997 or HCDCP after 1997). Since HCDCP has taken over the collection of data on confirmed malaria cases, active surveillance additionally occurs and on a weekly basis, HCDCP contacts local hospital laboratories to verify that the database is completely updated. In areas of Greece where possible domestic transmission is suspected, enhanced surveillance is implemented by tracing reported cases, visiting homes and performing personal or telephone interviews.

Following a short transition period after malaria elimination, malaria in Greece was limited to imported cases, with rare sporadic cases not related to travel $[8,9]$. Anopheles mosquitoes, which are potential Plasmodium vectors, nevertheless persisted in the country. Anopheles sacharovi, A. superpictus, and members of $A$. maculipenis complex are among the species that have been identified in Greece [10-14]. Entomological surveillance was performed occasionally in several parts of the country, however not on a regular basis.

In 2011, 27 autochthonous cases of malaria were detected in Evrotas, Lakonia [15]. Since then, an active surveillance system has been implemented in areas where malaria cases are reported in order to increase awareness among residents as well as to conclude on the control measures that should be taken and where.

The aim of this paper is to present a comprehensive report of malaria cases in Greece from 1975 to 2010, prior to the occurrence of the 2011 autochthonous cases [15].

\section{Methods}

Data on malaria laboratory-confirmed cases were collected for the period from 1975 to 2010. For the whole period, information on cases occurring via blood transfusion as well as on fatal cases was available from the $\mathrm{MoH}$ or HCDCP records. Information on confirmed cases' original clinical records and treatments, kept in the local hospitals, was also provided to $\mathrm{MoH}$ and then to HCDCP. It should be noted that during the 1975 to 1997 period, when cases were notified to $\mathrm{MoH}$, data on confirmed malaria cases also included information about the prefectural region where a case was recorded, sex, Plasmodium species and the type of infection (introduced, autochthonous, induced, relapse) [16]. During the period from 1975 to 1997 the age of the patient, profession, hospital, place of residence and travel information were only available for autochthonous or hospitalised cases.

In order to characterise a malaria case as introduced, the World Health Organization (WHO) guidelines were followed. The exact definition refers to a case that comes from transmission from imported case in an area where malaria does not occur regularly. According to WHO, 'a case in which it can be proved that the infection is a first step (first generation) of local transmission subsequent to a proved imported case i.e. in which the mosquito was infected from an imported case' [16].

From 1997 onwards, when HCDCP took over the surveillance and data collection of laboratory-confirmed malaria cases, additional information was recorded such as travel history, country of origin, and visiting friends and relatives. Age information is routinely recorded since 2002.

Regarding the location of acquisition, data is provided only for the period starting from 1999 when the cooperation of MRL with Roll Back Malaria Office became more intense. HCDCP since 1999, interviews all patients characterised as malaria cases to collect and confirm information.

P. falciparum malaria cases were classified and recorded as severe if they presented with anaemia, acute respiratory distress syndrome with metabolic acidosis, shock, abnormal bleeding and/or disseminated intravascular coagulation, jaundice, parasitaemia $>5 \%$ or cerebral malaria [17].

\section{Results}

From 1975 to 2010, a total of 1,419 laboratory-confirmed malaria cases were diagnosed by MRL and initially reported to $\mathrm{MoH}$ and, after 1997, to the HCDCP. The mean annual number of reported cases was 39.4, ranging from 16 (in 1997) to 79 cases (in 1978 and 1982). From 1975 to 1991, the mean annual number of cases was 49.8 (range: 28 in 1990 to 79 in 1978), but decreased to 27.8 in the 1992 to 2008 period (range: 16 in 1997 to 43 in 2003). During 2009 and 2010, a new increase in the total number of malaria cases was recorded (in 2009 the total annual number was 51 and in 2010 the total annual number was 48). All patients received appropriate anti-malarial treatment. Depending on the Plasmodium species being recognised and the patient's clinical status, quinine, mefloquine, chloroquine and primaquine were the anti-malarials of choice. In two severe malaria cases, artesunate was used.

One fatal case was recorded in 2003, in a man from Albania in his thirties, who had travelled to Cameroon for occupational reasons. Three days after his return to Greece, he developed malaise, chills and headache that lasted two days. On the sixth day he developed high fever and presented to his general practitioner who noticed altered mental status and he was admitted to hospital the same day. The diagnosis of malaria was made on the second day of his hospitalisation. Examination of peripheral blood showed mixed infection by $P$. falciparum and $P$. vivax. After his admission to the hospital, he showed pronounced anaemia, impaired renal function and developed acute respiratory distress syndrome. Treatment started immediately after diagnosis with intravenous quinine and doxycycline. His condition deteriorated and five days after his admission to the hospital, he died. 
TABLE

Number of malaria cases by Plasmodium species, Greece, 1975-2010 (n=1,419)

\begin{tabular}{|c|c|c|c|c|c|c|c|c|}
\hline Year & $\begin{array}{l}\text { Plasmodium } \\
\text { vivax } \\
\mathbf{n}(\%)\end{array}$ & $\begin{array}{c}\text { P. falciparum } \\
\mathbf{n}(\%)\end{array}$ & $\begin{array}{l}\text { P. malariae } \\
\mathbf{n}(\%)\end{array}$ & $\begin{array}{c}\text { P. ovale } \\
\text { n (\%) }\end{array}$ & $\begin{array}{l}P . \text { vivax, } P \text {. } \\
\text { malariae } \\
\mathbf{n}(\%)\end{array}$ & $\begin{array}{l}\text { P. vivax, } P \text {. } \\
\text { falciparum } \\
\mathbf{n}(\%)\end{array}$ & $\begin{array}{c}\text { Not identified } \\
n(\%)\end{array}$ & $\begin{array}{c}\text { Total } \\
\mathbf{n}\end{array}$ \\
\hline 1975 & $14(41)$ & $13(15)$ & $5(6)$ & $\mathrm{o}(\mathrm{o})$ & $\mathrm{o}(\mathrm{o})$ & $\mathrm{o}(\mathrm{o})$ & $2(0)$ & 34 \\
\hline 1976 & $19(46)$ & $11(27)$ & $9(22)$ & $\mathrm{O}(\mathrm{o})$ & $\mathrm{o}(\mathrm{o})$ & $\mathrm{o}(\mathrm{o})$ & $2(5)$ & 41 \\
\hline 1977 & $18(37)$ & $16(33)$ & 6 (17) & $\mathrm{o}(\mathrm{o})$ & o (o) & $\mathrm{o}(\mathrm{o})$ & 8 (13) & 48 \\
\hline 1978 & $32(40)$ & $32(41)$ & $11(14)$ & o (o) & o (o) & o (o) & $4(5)$ & 79 \\
\hline 1979 & $16(36)$ & $15(34)$ & $10(23)$ & $\mathrm{o}(\mathrm{o})$ & o (o) & $\mathrm{o}(\mathrm{o})$ & $3(7)$ & 44 \\
\hline 1980 & $22(41)$ & $19(36)$ & $10(19)$ & o (o) & o (o) & o (o) & $2(4)$ & 53 \\
\hline 1981 & $22(42)$ & 27 (34) & $14(22)$ & o (o) & $\mathrm{o}(\mathrm{o})$ & o (o) & $1(2)$ & 64 \\
\hline 1982 & $30(41)$ & $32(38)$ & $16(20)$ & o (o) & $\mathrm{o}(\mathrm{o})$ & $\mathrm{o}(\mathrm{o})$ & $1(1)$ & 79 \\
\hline 1983 & $16(39)$ & $17(36)$ & $10(23)$ & $\mathrm{o}(\mathrm{o})$ & o (o) & $\mathrm{o}(\mathrm{o})$ & $1(2)$ & 44 \\
\hline 1984 & $21(47)$ & $24(41)$ & 6 (12) & o (o) & o (o) & o (o) & o (o) & 51 \\
\hline 1985 & $13(38)$ & 16 (31) & $11(26)$ & o (o) & o (o) & o (o) & $2(5)$ & 42 \\
\hline 1986 & $16(57)$ & $23(40)$ & o (o) & $\mathrm{o}(\mathrm{o})$ & $\mathrm{o}(\mathrm{o})$ & $\mathrm{o}(\mathrm{o})$ & $1(4)$ & 40 \\
\hline 1987 & $14(57)$ & $30(27)$ & $5(10)$ & o (o) & o (o) & o (o) & $3(6)$ & 52 \\
\hline 1988 & $10(66)$ & 36 (18) & $5(9)$ & $\mathrm{o}(\mathrm{o})$ & o (o) & o (o) & $4(7)$ & 55 \\
\hline 1989 & 8 (17) & $29(60)$ & $3(6)$ & o (o) & o (o) & o (o) & 8 (17) & 48 \\
\hline 1990 & $8(29)$ & $16(56)$ & $1(4)$ & $\mathrm{o}(\mathrm{o})$ & o (o) & $\mathrm{o}(\mathrm{o})$ & $3(11)$ & 28 \\
\hline 1991 & $16(36)$ & $20(44)$ & $3(7)$ & o (o) & o (o) & o (o) & 6 (13) & 45 \\
\hline 1992 & $7(24)$ & $9(31)$ & $2(7)$ & o (o) & o (o) & o (o) & $11(38)$ & 29 \\
\hline 1993 & $11(55)$ & $19(31)$ & $5(14)$ & o (o) & o (o) & $\mathrm{o}(\mathrm{o})$ & o (o) & 35 \\
\hline 1994 & $8(30)$ & $10(37)$ & $3(11)$ & o (o) & o (o) & o (o) & $6(22)$ & 27 \\
\hline 1995 & $13(54)$ & $6(25)$ & $\mathrm{o}(\mathrm{o})$ & o (o) & $\mathrm{o}(\mathrm{o})$ & $\mathrm{o}(\mathrm{o})$ & $5(21)$ & 24 \\
\hline 1996 & 9 (39) & $8(35)$ & $\mathrm{o}(\mathrm{o})$ & $\mathrm{o}(\mathrm{o})$ & o (o) & $\mathrm{o}(\mathrm{o})$ & $6(26)$ & 23 \\
\hline 1997 & $5(31)$ & $6(38)$ & o (o) & o (o) & $\mathrm{O}(\mathrm{o})$ & o (o) & $5(31)$ & 16 \\
\hline 1998 & $9(38)$ & $10(41)$ & $1(4)$ & $1(4)$ & o (o) & o (o) & $3(13)$ & 24 \\
\hline 1999 & $11(44)$ & $9(36)$ & o (o) & o (o) & o (o) & o (o) & $5(20)$ & 25 \\
\hline 2000 & $10(32)$ & $14(46)$ & $\mathrm{o}(\mathrm{o})$ & $1(3)$ & $\mathrm{o}(\mathrm{o})$ & $\mathrm{o}(\mathrm{o})$ & 6 (19) & 31 \\
\hline 2001 & $4(13)$ & $16(53)$ & o (o) & $2(7)$ & o (o) & o (o) & $8(27)$ & 30 \\
\hline 2002 & $7(28)$ & $14(56)$ & o (o) & $1(4)$ & $1(4)$ & $1(4)$ & $1(4)$ & 25 \\
\hline 2003 & $15(35)$ & $26(61)$ & o (o) & $1(2)$ & o (o) & o (o) & $1(2)$ & 43 \\
\hline 2004 & $14(41)$ & $19(56)$ & $1(3)$ & $\mathrm{o}(\mathrm{o})$ & $\mathrm{O}(\mathrm{o})$ & o (o) & o (o) & 34 \\
\hline 2005 & $9(48)$ & $9(47)$ & $1(5)$ & $\mathrm{o}(\mathrm{o})$ & $\mathrm{o}(\mathrm{o})$ & $\mathrm{o}(\mathrm{o})$ & $\mathrm{o}(\mathrm{o})$ & 19 \\
\hline 2006 & $9(29)$ & $20(65)$ & $1(3)$ & $1(3)$ & o (o) & o (o) & o (o) & 31 \\
\hline 2007 & $10(47)$ & $9(43)$ & $1(5)$ & o (o) & o (o) & o (o) & $1(5)$ & 21 \\
\hline 2008 & $27(75)$ & $8(22)$ & o (o) & o (o) & $\mathrm{o}(\mathrm{o})$ & $\mathrm{o}(0)$ & $1(3)$ & 36 \\
\hline 2009 & $23(45)$ & $24(47)$ & $1(2)$ & $\mathrm{o}(\mathrm{o})$ & $\mathrm{o}(\mathrm{o})$ & $2(4)$ & $1(6)$ & 51 \\
\hline 2010 & $28(55)$ & 16 (31) & o (o) & $1(2)$ & $1(2)$ & $1(2)$ & $1(2)$ & 48 \\
\hline Total & $524(37)$ & $628(44)$ & 141 (10) & $8(1)$ & $2(0)$ & $4(0)$ & $112(8)$ & 1,419 \\
\hline
\end{tabular}




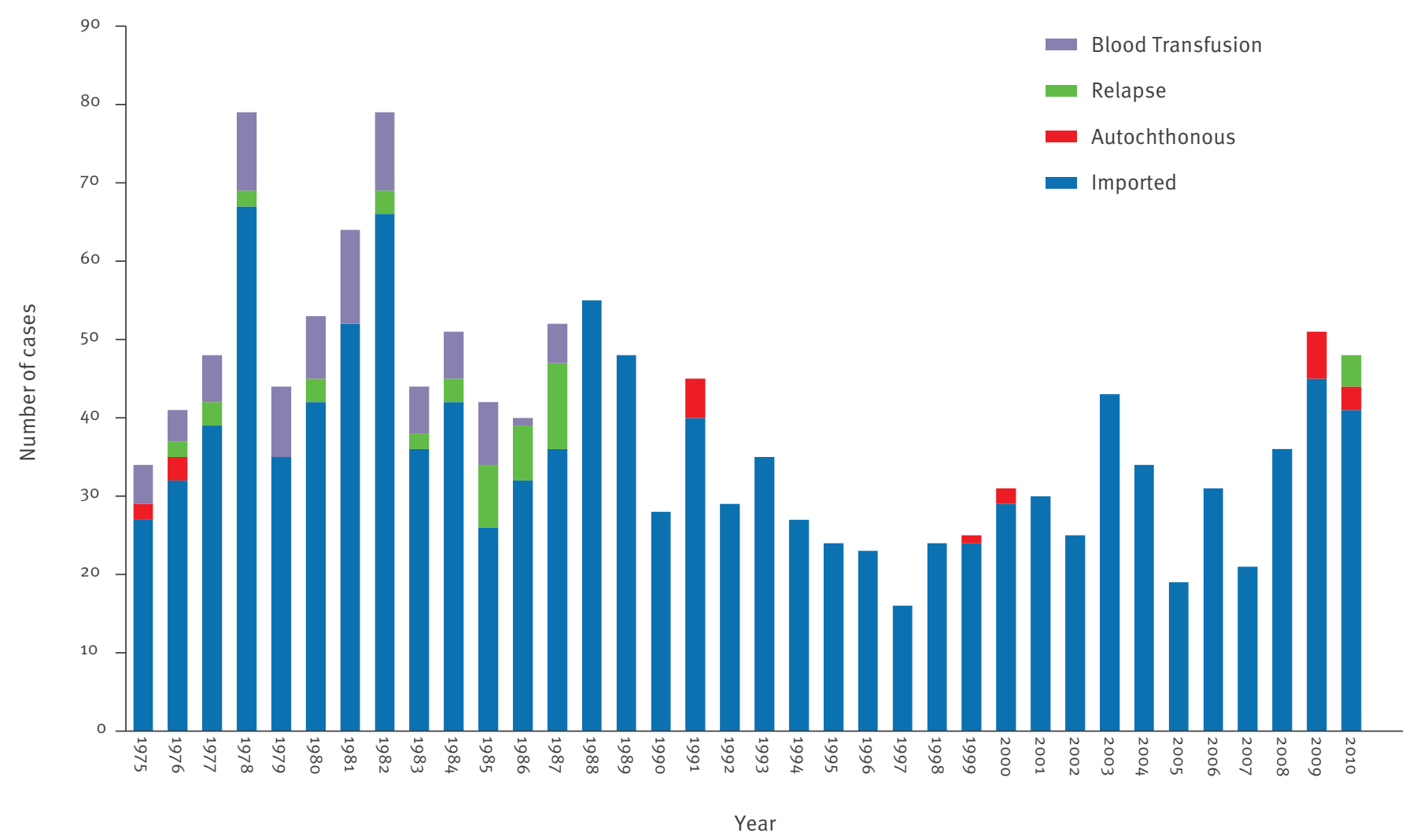

To our knowledge, there were three severe cases of malaria in Greek citizens. These occurred in the period from 1992 to 2010, and concerned two adults who had travelled to north-east Asia and an 11 year-old child who had travelled to Tanzania. In all these cases, chemoprophylaxis was either incomplete or absent. The first two individuals sought medical assistance with delay, while the child received insufficient doses of the antimalarial drug.

\section{Sex and age distribution}

Of all 1,419 malaria cases, 1,123 (79\%) were male and $296(21 \%)$ female. Of the 490 cases for whom age was known, the age distribution was between six months and 89 years with a median age of 31 years. The 18 to 64 year age group comprised 416 cases (85\%) and 352 cases $(72 \%)$ were aged between 18 and 40 years. Ten cases ( $2 \%$ ) were over 65 years-old, while 14 cases $(3 \%)$ were less than five years-old, $16(3 \%)$ were aged between five and 12 years and 34 (7\%) were aged between 13 and 17 years giving a total of 64 cases $(13 \%)$ in the category below and up to 17 years of age.

\section{Plasmodia species}

Most cases were infected with $P$. falciparum $(n=628$, 44\%), 524 (37\%) with $P$. vivax, and 141 (10\%) with $P$. malariae, while only eight cases $(\leqslant 1 \%)$ were due to $P$. ovale. Four cases ( $₫ 1 \%)$ presented with a mixed
$P$. falciparum/P. vivax infection, two ( $11 \%)$ acquired a mixed $P$. vivax /P. malariae infection and in 112 cases $(8 \%)$ the species was not identified. Mixed $P$. falciparum and $P$. malariae infections were never detected. The highest number of $P$. falciparum infections $(n=36)$ was reported in 1988 and the lowest $(n=6)$ in the years 1995 and 1997, whereas for $P$. vivax the highest number $(n=32)$ was recorded in 1978 and the lowest $(n=4)$ in 2001 (Table).

\section{Source of malaria infection}

Of all 1,419 reported malaria cases, 1,259 (89\%) were classified as imported. Ninety cases (13\%) of the 671 malaria cases during the period from 1975 to 1987 were due to blood transfusion, with the last one reported in 1987, according to $\mathrm{MoH}$ records. From 1975 to 2009, among a total 1,371 malaria cases, 44 cases ( $3 \%$ ) of $P$. vivax relapse were found, while in 2010 , four cases of relapse occurred among migrants who lived and worked for a few months in Greece. The latter cases reported previous episodes of malaria in the country of origin, thus suggesting, according to the official definition, that their infection was due to relapse [16]. The majority of cases reported from 1988 onwards were imported $(731 / 748,98 \%)$ and only $17(2 \%)$ of the cases were not related to travel and possibly introduced (Figure 1). 
Region of acquisition of infection

Of all 382 imported and relapse cases reported since 1999, 133 (35\%) were in Greeks and 249 (65\%) in migrants.

A total of 210 migrants from Africa as well as individuals travelling to and from Africa accounted for $55 \%$ of malaria cases (mainly from sub-Saharan countries of Central West Africa). In addition, 142 (37\%) cases, including four cases of relapses, acquired their infection in Asia (mainly in Pakistan, India and Bangladesh). The World Health Organisation European Region accounted for five cases (1\%) without further information on their travel history. According to their declaration, these cases were of European origin, specifically from eastern Europe, Russian Federation, Georgia and Kazakhstan. While from 1999 to 2005, the majority of imported cases originated from Africa, the pattern has changed since 2006, with cases originating from Asia accounting for the majority of imported cases (Figure 2).

\section{Autochthonous cases}

In 1975 and 1976, two and three cases without travel history to a malarious country, were reported respectively, but no other autochthonous cases were reported until 1991. In 1991, five introduced autochthonous cases were reported from the prefectural regions of East Attica and Viotia in central Greece ( 3 and 2 cases, respectively) (Figure 3), where a large population of non-documented migrants originating from malaria endemic countries worked seasonally. All cases were recorded between 26 of July and 27 of August 1991 and were hospitalised in Athens.

The first of the two cases in Viotia was caused by $P$. vivax and involved a girl who was treated with chloroquine. The second case was due to $P$. falciparum and concerned a man in his sixties, who had agriculturalrelated activities. He was treated with quinine and doxycycline. This autochthonous $P$. falciparum case was directly reported to the related Department of the Ministry of Health, examination of the sample was performed, but the sample was not sent to the MRL for verification.

In East Attica, the three reported cases were infected with $P$. vivax. The first was a teenager who was a student and had visited the Rafina area, the second, a girl, who was in the Avlaki area on vacation and the third, a male student in his teens who had repeatedly visited the area of Schinias. All cases were successfully treated with chloroquine and primaquine.

Another case was detected in 1999 in the prefectural region of Fthiotida (central Greece). In 2000, two cases were detected in a tourist resort area in the prefectural region of Chalkidiki, northern Greece. These two malaria cases concerned German tourists, who were diagnosed with malaria after returning to their country. The epidemiological investigation revealed that

\section{FIGURE 2}

Number of malaria cases according to the continent of acquisition of infection, Greece 1999-2010 ( $n=382)$

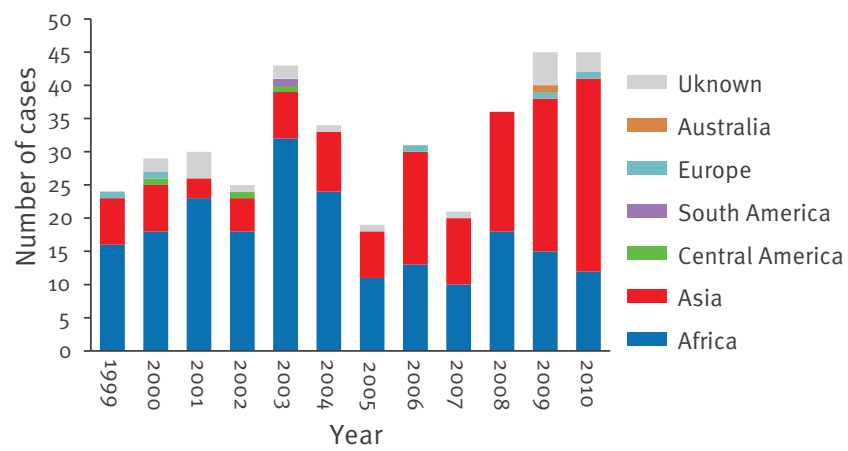

they both stayed in the same hotel as a tourist from Mozambique who had at least six recent malaria episodes. In 2009, a cluster of six cases without travel history to a malarious country occurred in the municipality of Evrotas (prefectural region of Lakonia, Peloponisos) in southern Greece. Four of those cases were Greek Roma, residing in a camp.

In 2010, three new autochthonous cases were reported, two in the prefectural region of Viotia, and one, in a Greek Roma from the same area as the 2009 cluster (prefectural region of Lakonia). The cases in Viotia were two Greek Roma children aged less than seven years. Regarding the Roma population, after several discussions with the local authorities, we were informed that they had travelled within the Greek borders and not in malaria endemic countries. In addition, four individual cases of autochthonous malaria in the prefectural region of Evros, northern Greece have been diagnosed, but they have never been verified nor reported to the health authorities [8].

\section{Discussion}

The anti-malarial campaign in Greece was labour-intensive and long lasting. Local and foreign authorities, in collaboration with scientific centres, such as the Rockfeller Institution, most contributed to achieving the main goal of eliminating malaria [18-20].

This effort, although interrupted during World War II, subsequently continued intensively even with limited available resources. Finally, at the end of the 1960s, Greece was considered as a malaria-free country, with the official recognition for elimination occurring in 1974 [4]. The first following years were characterised by the loosening and insufficient application of surveillance measures, together with abolishment of the existing malaria control centres during the 1980 .

Nevertheless, since 1974, a considerable number of imported cases have been reported in Greece, as also 


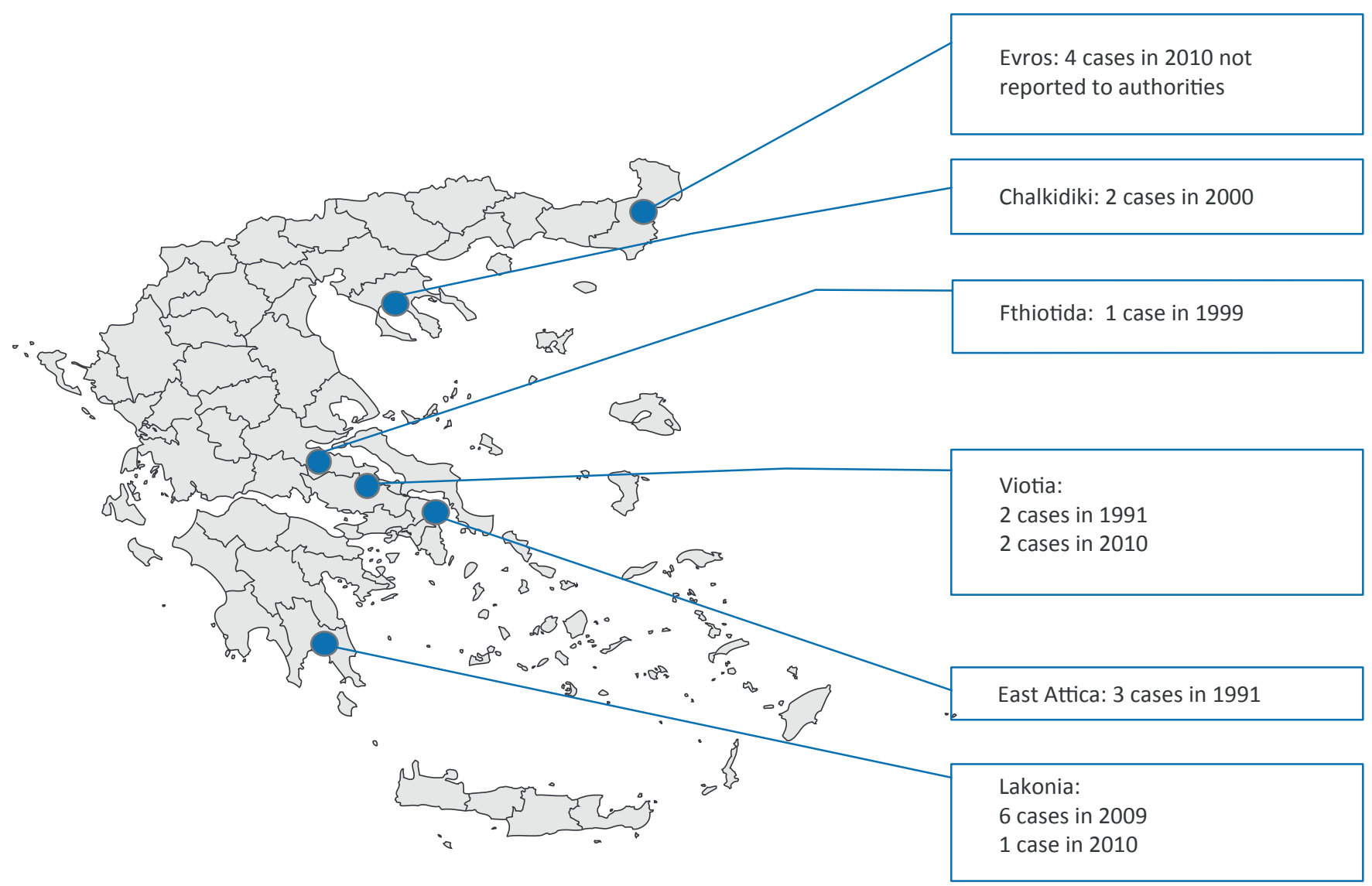

in several other European countries such as France, Germany, Italy, and the United Kingdom [21-24].

Malaria cases due to blood transfusion were not observed in Greece after 1987. This can be attributed to the implementation of a strict policy on blood management, mainly based on careful selection and exclusion of donors and where necessary, laboratory testing of donated blood. One death from malaria was reported in Greece during the study period. A presumable explanation for the very low case fatality rate may be the early malaria suspicion that was critical for confirmation of the diagnosis. Another reason might be the fortunate coincidence of the sensitivity of the $P$. falciparum strains to quinine, which was always available immediately from the public health authorities of the $\mathrm{MoH}$. It would be difficult to assume non-reporting of malaria deaths. Of course this cannot be excluded, however only in non-diagnosed cases.

As it already has been mentioned, in Greece, large populations of Anopheles mosquitoes, which are competent Plasmodium vectors, have been recognised ( $A$. maculipenis, $A$. sacharovi, $A$. superpictus). In certain parts of the country, due to the presence of rice fields and suitable habitats, mosquito populations are abundant. As far as the vectorial competence of local Anopheles to carry $P$. falciparum, it should be mentioned that since the period when malaria was endemic in Greece, the competence of several species ( $A$. sacharovi, $A$. maculipenis, $A$. superpictus) to carry the four Plasmodium species was proven, with $A$. sacharovi being the most prevalent species. Studies from the past [25] have shown on the basis of over 50,000 dissections, that $A$. sacharovi is the most competent vector with a sporozoite rate of $1.3 \%$, followed by $A$. superpictus with $0.8 \%$ and $A$. maculipenis with $0.07 \%$. During the 1930 s the distribution of malaria parasites among human cases, was $49 \%$. falciparum, $27 \% P$. vivax and $22 \% P$. malariae [26].

Moreover, where autochthonous malaria cases were recorded, Anopheles mosquitoes of the species sacharovi and members of the maculipenis complex have been recognised occasionally. However, data on their behaviour, habits and host biting preferences is missing. So far, there is no documented study concerning other Anopheles species present in Greece, such as $A$. hyrcanus and $A$. claviger, which are also considered to be potential malaria vectors.

As between 1977 and 1990 no autochthonous cases had been recorded in Greece, the occurrence of domestic cases of malaria after 1990 could be attributed to the presence of imported cases from malaria endemic countries. This is also supported by the fact that 
autochthonous cases appeared during periods of mass entry of undocumented economic migrants, especially from countries where malaria is endemic. After extensive investigation, five autochthonous cases in 1991, one in 1999, two in 2000, six in 2009 and three in 2010 were reported in areas that can be considered as potentially prone to malaria. A few other cases in the Prefectural region of Evros, close to the borders with Turkey were reported, which were never confirmed from the authorised healthcare providers [8]. All but one of the autochthonous cases of malaria were due to $P$. vivax. A genotyping study of plasmodia is currently in progress.

Autochthonous malaria cases in other European countries were also sporadically reported (Italy 1997, Bulgaria 1995 and 1996, Germany 2001, France 2007) $[27,28]$. In Spain, the first autochthonous case of $P$. vivax malaria was diagnosed 40 years after elimination; nevertheless, the source of infection could not be identified [29]. Since 2000, a rather impressive outbreak in Turkey and the former Soviet Union countries caused by $P$. vivax and $P$. falciparum has been documented [30]. The prompt implementation of malaria control measures reduced dramatically the number of malaria cases to 176 (in Azerbaijan, Kyrgyzstan, Tajikistan, Turkey and Uzbekistan), as opposed to 90,712 in the year 1995 [30].

In Greece, the frequency of identified Plasmodium species in human malaria cases is almost the same as in other Mediterranean countries [22,24,28,29]. Initially, the majority of imported cases originated from Africa, but since 2009 most originate from Asia. In the United States, from 2000 to 2008 , a similar increase in malaria cases originating from Asia was also observed [31,32]. The problem of individuals who became cases while visiting friends and relatives in an endemic area also exists in Greece but to a lesser extent. Travellers of this group, rarely visit the pre-travel health services before their trip. Furthermore, many of them do not receive proper anti-malarial chemoprophylaxis as they believe that they are protected by life-long immunity against malaria [33].

All cases but one were successfully treated based on existing experience and recommendations of WHO and Centers for Disease Control and Prevention (CDC) [34-36].

On the basis of the data presented and considering the recent $P$. vivax malaria cases of 2011 in the Lakonia area as well as the $P$. vivax malaria cases of 2012 in the Lakonia and East Attica areas [15,37], it is clear that surveillance and vector control programmes should be strengthened and rapidly intensified. In this respect, a coordinated effort has begun with the collaboration of Greek authorities, the European Centre for Disease Prevention and Control (ECDC) and WHO experts, to prevent potential malaria reestablishment.
References

1. Ntafoulis P. Sir Ronald Ross's participation in the Greek antimalaria fight in 1906. Archives of Hellenic Medicine. 2008; 25(2):248-54.

2. Savvas K, Kardamatis J. I Elonosia en Elladi kai ta pepragmena tou Sullogou [Malaria in Greece and the actions of the Association]. Athens; 1928 .Greek.

3. Livadas GA. I Elonosia. [The Malaria]. Athens: Livadas GA; 1955. Greek.

4. Bruce-Chwatt L, de Zulueta J. The rise and fall of malaria in Europe: a historico-epidemiological study. Oxford: Oxford University Press; 1980, p. 18-25.

5. Vakalis N. I simvoli tis ygeionomikis sxolis Athinon ston anthelonosiako agona [The contribution of Athens School of Hygiene in the antimalarial campaign]. Deltos Journal of the history of Hellenic Medicine. 2005; 30: 56-64.Greek.

6. Belios GD. Course of Malaria in Greece during the recent years. Evaluated on basis of the 1949 reported malaria deaths in towns and other available epidemiological data. Archives of Hygiene. 1950; 1(4-6): 191-206.

7. Patsoula E, Spanakos G, Sofianatou D, Parara M, Vakalis NC. A single step, PCR-based method for the detection and differentiation of Plasmodium vivax and P. falciparum. Ann Trop Med Parasitol. 2003; 97(1):15-21.

8. Kampen H, Proft J, Etti S, Maltezos E, Pagonaki M, Maier WA, et al. Individual cases of autochthonous malaria in Evros Province, Northern Greece: entomological aspects. Parasitol Res. 2003; 89(4): 252-8.

9. Vakalis N. Epidemiological surveillance of malaria in countries of central and eastern Europe and selected independent states, Greece. Report on a WHO intercountry meeting. Sofia, Bulgaria. 2002. Copenhagen: World Health Organization Regional Office for Europe; 2002. p. 10. Available from: http:// www.euro.who.int/_data/assets/pdf_file/0006/98781/ E77302.pdf

10. Samanidou-Vogiatzoglou A, Darsie RF Jr. An annotated checklist and bibliography of the mosquitoes of Greece (Diptera: Culicidae). Mosq Syst. 1993; 25(3):177-85.

11. Darsie RF Jr, Samanidou-Vogiatzoglou A. Keys for the identification of the mosquitoes of Greece. J Am Mosq Control Assoc. 1997; 13(3): 247-54.

12. Samanidou-Voyadjoglou A. Malaria vectors in Greece. In: Proceedings of the 1st Balkan Conference. Malaria and Mosquito Control; 2001: Serres, Greece. p. 62-65.

13. Linton YM, Smith L, Koliopoulos G, Zounos AK, SamanidouVogiadjoglou A, Patsoula E, et al. The Anopheles (Anopheles) maculipenis complex (Diptera: Culicidae) in Greece. Journal of Natural History. 2007; 41(41-44): 2683-99

14. Patsoula E, Samanidou-Voyadjoglou A, Spanakos G, Kremastinou T, Nasioulas G, Vakalis N Molecular characterizasation of the Anopheles maculipennis complex during surveillance for the 2004 Olympic Games in Athens. Med Vet Entomol. 2007; 21(1): 36-43.

15. Danis K, Baka A, Lenglet A, Van Bortel W, Terzaki I, Tseroni $M$, et al. Autochthonous Plasmodium vivax malaria in Greece, 2011. Euro Surveill. 2011; 16(42):pii=19993. Available from: http://www.eurosurveillance.org/ViewArticle. aspx?Articleld=19993

16. World Health Organization (WHO). Malaria elimination. A field manual for low and moderate endemic countries. Geneva: WHO Press; 2007. WHO. p.81

17. Severe falciparum malaria. World Health Organization, Communicable Diseases Cluster. Trans R Soc Trop Med Hyg. 2000;94 Suppl 1: S1-S90.

18. Balfour MC. Malaria studies in Greece. Measurements of Malaria, 1930-1933. Am J Trop Med Hyg. 1935; S1-15(3): 301-30.

19. Belios GD. Recent course and current pattern of malaria in relation with its control in Greece. Riv Malariol. 1955; 34(1-3): 1-24.

20. Livadas G, Belios G. World Health Organization Expert Commitee in Malaria. Post war malaria control in Greece and its results on basis of epidemiological data. 1948: Geneva: WHO; 1948.

21. Legros F, Danis M. Surveillance of malaria in European Union countries. Euro Surveill. 1998;3(5):pii=103. Available from: http://www.eurosurveillance.org/ViewArticle. aspx?Articleld $=103$

22. Sabatinelli G, Ejov M, Joergensen P. Malaria in the WHO European Region (1971-1999). Euro Surveill. 2001;6(4):pii=213. Available from: http://www.eurosurveillance.org/ViewArticle. aspx?Articleld $=213$

23. Bradley DJ, Warhurst DC, Blaze M, Smith V, Williams J. Malaria imported into the United Kingdom in 1996. Euro 
Surveill. 1998;3(4):pii=107. Available from: http://www. eurosurveillance.org/ViewArticle. aspx?Articleld=107

24. Jelinek T. Imported Falciparum malaria in Europe: 2007 data from TropNetEurop. Euro Surveill. 2008;13(23): pii=18895.

Available from: http://www.eurosurveillance.org/ViewArticle. aspx?Articleld $=18895$

25. Barber MA, Rice JB. Malaria studies in Greece. Ann Trop Med Parasitol. 1935;29: 329-48.

26. Bruce-Chwatt LJ, Draper CC. World Health Organization (WHO) Regional Office for Europe. Some aspects of malaria eradication in Greece. Report on a mission to Greece. WHO: Geneva: Sep 1974.

27. Kruger A, Rech A, Su XZ, Tannich E. Two cases of autochthonous Plasmodium falciparum malaria in Germany with evidence for local transmission by indigenous Anopheles plumbeus. Trop Med Int Health. 2001; 6(12): 983-5.

28. Doudier B, Bogreau H, DeVries N, Poncon N, Stauffer W, Fontenille D, et al. Possible autochthonous malaria from Marseille to Minneapolis. Emerg Infect Dis. 2007; 13(8):1236-8.

29. Santa-Otalla Peralta P, Vasquez-Torres MC, Latorre-Fandos E, Mairal-Claver P, Cortina-Solano P, Puy-Azon A et al. First autochthonous malaria case due to Plasmodium vivax since eradication, Spain, October 2010. Euro Surveill. 2010;15(41):pii=19684. Available from: http://www. eurosurveillance.org/ViewArticle.aspx?Articleld $=19684$

30. World Health Organization. Eliminating Malaria: Learning From the Past, Looking Ahead. Progress and Impact Series. 2011; 8:43-46.

31. Mali S, Steele S, Slutsker L, Arguin PM; Centers for Disease Control and Prevention (CDC). Malaria surveillance - United States, 2007. MMWR Surveill Summ. 2009; 58(2):1-16.

32. Mali S, Steele S, Slutsker L, Arguin PM; Centers for Disease Control and Prevention (CDC). Malaria surveillance - United States, 2008. MMWR Surveill Summ. 2010; 59(7):1-15.

33. Pavli A, Maltezou HC. Malaria and travellers visiting friends and relatives. Travel Med Infect Dis. 2010; 8(3): 161-8.

34. Centers for Disease Control and Prevention (CDC). Malaria Treatment (United States). Atlanta: CDC. [Accessed: 20 Nov 2012]. Available from: http://www.cdc.gov/malaria/diagnosis_ treatment/treatment.html

35. World Health Organization (WHO). Guidelines for the treatment if Malaria. Geneva: WHO; 2006.

36. Warrell DA. Treatment and prevention of malaria. In: Gilles HM, Warrell DA, editors. Bruce-Chwatt's essential malariology, 3rd edition. London: E Arnold; 1993.

37. European Centre for Disease Prevention and Control (ECDC). Communicable disease threats report (CDTR) Week 37, 9-15 September 2012. Stockholm: ECDC. [Accessed 20 Nov 2012]. Available from: http://ecdc.europa.eu/en/publications/ Publications/ECDC_CDTR_9.15.12.pdf 